\title{
Fatores que interferem no processo de inclusão de bebês com deficiência física no berçário
}

\author{
Tatiele Jacques Bossi', https://orcid.org/0000-0003-0487-8112
}

Ana Paula Pedroso Junges ${ }^{1}$, https://orcid.org/0000-0003-4610-7930

Cesar Augusto Piccinini' ${ }^{1}$, https://orcid.org/0000-0002-4313-3247

\begin{abstract}
Resumo
Este estudo teve por objetivo investigar os fatores que interferem no processo de inclusão de bebês com deficiência física no berçário, na perspectiva das educadoras. Participaram 11 educadoras de duas creches públicas que tinham bebês com deficiência física incluídos no berçário. A análise qualitativa dos relatos das educadoras apontou diversos fatores que interferem na inclusão, atribuídos às educadoras, ao bebê com deficiência e seus colegas, à creche, ao município e a outros profissionais. Nenhum aspecto foi ressaltado com relação à família dos bebês com deficiência, o que remete à dificuldade das educadoras em perceber as famílias como agentes da inclusão. Salienta-se que mesmo transcorridos mais de 20 anos das principais declarações e leis que representam as políticas de educação na perspectiva inclusiva, a inclusão ainda ocorre de forma incipiente, sem que se dedique prioridade de investimentos na educação. Isso remete à necessidade de pesquisas e intervenções na área. Palavras-chave: Inclusão; creches; deficiente físico.
\end{abstract}

\section{Factors that interfere with the process of inclusion of infants with physical disability in the nursery}

\begin{abstract}
This study aimed to investigate the factors that interfere in the process of inclusion of infants with physical disabilities in the nursery, from the educators' perspective. Eleven educators from two public daycare centers that had children with physical disabilities included in the nursery participated. The qualitative analysis of the educators' reports pointed to several factors that interfere in the inclusion, attributed to the educators, the disabled baby, and his colleagues, the daycare center, the municipality and other professionals. No aspect was pointed out regarding the family of infants with disabilities, which refers to the difficulty of educators in perceiving families as agents of inclusion. It should be noted that even after more than 20 years of the main declarations and laws that represent education policies in an inclusive perspective, inclusion still occurs in an incipient way, without prioritizing investments in education. This points to the need for research and interventions in the area.
\end{abstract}

Keywords: Inclusion; child day care; physically disabled.

\section{Factores que interfieren en el proceso de inclusión de bebés con discapacidad física en la guardería}

\begin{abstract}
Resumen
En este estudio se tuvo por objetivo investigar los factores que interfieren en el proceso de inclusión de bebés con discapacidad física en la guardería, en la perspectiva de las educadoras. Participaron 11 educadoras de dos guarderías públicas que tenían bebés con discapacidad física incluidos en la guardería. El análisis cualitativo de los relatos de las educadoras apuntó diversos factores que interfieren en la inclusión, atribuidos a las educadoras; al bebé con discapacidad y sus compañeros; y, a la guardería, al municipio y a otros profesionales. Ningún aspecto fue resaltado con relación a la familia de los bebés con discapacidad, lo que remete a la dificultad de las educadoras en percibir las familias como agentes de la inclusión. Se subraya que, aunque transcurridos más de 20 años de las principales declaraciones y leyes que representan las políticas de educación en la perspectiva inclusiva, la inclusión aún ocurre de forma incipiente, sin que se dedique prioridad de inversiones en la educación. Eso remite la necesidad de investigaciones e intervenciones en el área.
\end{abstract}

Palabras clave: Inclusión; jardines infantiles; deficiente físico.

1 Universidade Federal do Rio Grande do Sul - Porto Alegre - RS - Brasil; tatielejbossi@gmail.com; anapjunges@gmail.com; piccinini@portoweb.com.br 


\section{Introdução}

Segundo o Censo de 2010 (Brasil, 2012), 23,9\% da população brasileira possui algum tipo de deficiência auditiva, visual, motora e/ou intelectual. No grupo de pessoas entre 0 a 4 anos, a deficiência atinge $2,79 \%$ da população (cerca de cinco milhões de crianças) e esta, por direito, deveria ser incluída na educação infantil, ao respeitar a política de inclusão que preconiza que toda a educação básica deve ser oferecida em escolas comuns de ensino (Lei $n^{\circ}$ 9.394, 1996). Segundo o INEP (2014), houve um aumento de 6,2\% no número de matrículas de crianças com deficiência na educação infantil ( 0 a 5 anos) em 2013 quando comparado ao ano anterior. Já entre 2007 a 2013 o aumento foi de $42 \%$.

A Declaração de Salamanca (UNESCO, 1994) define a escola inclusiva como aquela que segue o princípio fundamental de que todas as crianças têm o direito de aprenderem juntas, independentemente das dificuldades ou diferenças que possuam, pois a escola deve se adaptar aos estilos e ritmos de aprendizagem de seus alunos, ao tornar o currículo e as estratégias de ensino mais apropriadas. Já o Referencial Curricular Nacional para a Educação Infantil (Brasil, 1998) reforça esses aspectos destacados, ao ressaltar que a escola inclusiva tem como desafio colocar em prática a concepção da pedagogia centrada na criança. Dessa forma, deve trabalhar com a diversidade, o respeito às diferenças e solicitar profissionais especializados quando isso se fizer necessário.

A partir do mencionado, é relevante dar atenção aos aspectos que podem auxiliar ou não o processo inclusivo, com destaque para aqueles referentes à educação infantil. O Referencial Curricular Nacional para a Educação Infantil (Brasil, 1998) aponta que a qualidade do processo inclusivo se relaciona a vários fatores tais como a idade, o grau de deficiência, as potencialidades e as limitações de cada criança, a disponibilidade e a qualidade dos recursos materiais e humanos, as condições socioeconômicas das famílias, dentre outros fatores. Além disso, o despreparo dos professores para trabalhar com o aluno com deficiência mostra-se, para alguns autores, como decisivo para a promoção da exclusão em um ambiente que deveria ser inclusivo, o que coloca a necessidade de se garantir a formação continuada sobre o tema (Dantas, 2012; Galceran, 2012; Sanini \& Bosa, 2015; Zucchetti, 2011).

Ainda é importante salientara falta de apoio pedagógico às educadoras, principalmente em estratégias que considerem a diversidade dos alunos; a importância das concepções positivas a respeito da capacidade de aprendizagem e de desenvolvimento satisfatório do aluno com deficiência; a necessidade de trabalho coletivo entre a escola (direção, coordenação e demais da equipe) e a família, bem como a necessidade de formação pedagógica mais direcionada para a educação especial que ainda apresenta-se como deficitária e tende a impactar na percepção e entendimento das educadoras com relação à inclusão (Dantas, 2012; Fragoso \& Casal, 2012; Galceran, 2012; Vitta, 2010; Zucchetti, 2011).

Por exemplo, o estudo de Fragoso e Casal (2012) teve por objetivo conhecer as representações sociais de 30 professores de educação infantil de Portugal referente à inclusão em escolas comuns de ensino. Os dados apontaram que as atitudes dos educadores frente à inclusão estavam relacionadas à sua formação que contemplava de forma precária a educação especial. Além disso, a experiência com crianças com necessidades educativas especiais, e o fato de considerarem que o seu trabalho com elas foi bem sucedido, tendeu a contribuir para uma visão mais positiva com relação à inclusão. No entanto, o estudo também apontou que a viabilidade do processo inclusivo estava relacionada a recursos técnicos, humanos e condições físicas disponíveis na escola. A falta de formação específica e de recursos, aspectos presentes de maneira expressiva nas escolas comuns de ensino, acabava por contribuir para uma representação social discriminatória por parte de alguns educadores, com relação às crianças incluídas nesse contexto. Isso, segundo os autores, promovia uma inclusão de forma limitada. No entanto, apesar desses aspectos pouco favoráveis ao processo inclusivo, a maioria dos educadores apresentou uma postura oposta, adotando representações sociais que indicavam uma atitude favorável à inclusão, tal como a de igualdade de oportunidades oferecidas às crianças. Atitude positiva com relação à inclusão também se fez presente em 24 professores de educação infantil do Zimbábue, apesar dos obstáculos sociais e culturais à prática da inclusão no país (Majoko, 2016).

Já o estudo de Vitta, Vitta e Monteiro (2010) teve por objetivo analisar a percepção de professores de escolas de educação infantil da cidade de Bauru/SP quanto a educação de crianças com deficiência com idades entre 3 e 6 anos. Participaram do estudo 12 professores, divididos igualmente em três grupos: professores de escolas especiais, professores de escola comum sem alunos com deficiência em suas turmas, e professores de escola comum com alunos com deficiência em suas turmas. Os professores destacaram a importância da inclusão para a socialização da criança, mas restringiram essa capacidade somente àquelas que apresentavam possibilidade de maior independência. Também foi destacado em todos os grupos o entendimento de que a inclusão não é para todos, já que em alguns casos considerados mais graves o atendimento educacional deveria ser oferecido em local especializado. Com relação à aprendizagem, consideraram que as crianças com deficiência intelectual apresentavam maiores dificuldades quando comparadas às crianças com deficiência física. Para estas, segundo os professores, as dificuldades de aprendizagem estavam relacionadas à falta de recursos que possibilitassem uma boa adaptação aos alunos e estimulasse a sua aprendizagem. Também ressaltaram os problemas referentes ao espaço físico das escolas (rampas, banheiros adaptados, portas mais largas, entre outros), os recursos materiais (material adaptado) e humanos (auxiliar em sala de aula), e a formação por parte do professor (necessidade de formação inicial, continuada e especialização), que ainda são entraves para que o processo de inclusão aconteça adequadamente. Com relação a este último aspecto, os participantes ressaltaram a necessidade do professor se sentir motivado a estudar $\mathrm{e}$ buscar informações sobre o tema. 
Tabela 1. Dados sociodemográficos das educadoras.

\begin{tabular}{lllll}
\hline Educadores & Idade (anos) & Escolaridade & Cargo & Escola \\
\hline E1 & 33 & Pós-graduação & Professora & A \\
\hline E2 & 41 & Superior incompleto & Estagiária & A \\
\hline E3 & 34 & Superior incompleto & Estagiária & A \\
\hline E4 & 27 & Pós-graduação & Professora & A \\
\hline E5 & 51 & Superior incompleto & Estagiária & A \\
\hline E6 & 32 & Pós-graduação & Professora & A \\
\hline E7 & 46 & Pós-graduação & Monitora & B \\
\hline E8 & 47 & Ensino médio completo & Monitora & B \\
\hline E9 & 43 & Pós-graduação & Professora & B \\
\hline E10 & 33 & Superior completo & Monitor & B \\
\hline E11 & 48 & Superior incompleto & Estagiária & B \\
\hline
\end{tabular}

Os estudos que ressaltam a educação infantil destacam a inclusão nas séries de maternal ou pré-escola, ou seja, entre 3 e 6 anos de idade (Al-Yagon, Aram, \& Margalit, 2016; Brandão \& Ferreira, 2013; Brodzeller, Ottley, Jung, \& Coogle, 2017; Lemos, Salomão, \& Agripino-Ramos, 2014; Sucuoglu, Bakkaloglu, Karasu, Demir, \& Akalin, 2014), e em menor número no primeiro ou segundo ano de vida (Vitta, 2010; Vitta, Silva, \& Moraes, 2004). Uma exceção é o estudo de Vitta (2010) que teve por objetivo investigar as concepções de sete educadoras de berçário, de duas creches de Bauru/SP, com relação à inclusão de bebês com deficiência em suas turmas. Os resultados apontaram que as educadoras demonstraram inseguranças quanto à possibilidade de incluir bebês com deficiência nas turmas de berçário. Isso acabava por refletir o desconhecimento delas com relação às deficiências, onde predominava o entendimento da deficiência como extremamente limitante na evolução do desenvolvimento do bebê. Algumas participantes apresentaram um discurso resistente à inclusão, utilizando como justificativa o fato de que os bebês com deficiência necessitavam de atenção exclusiva e tendiam a não apresentar evolução no desenvolvimento. Já com relação às dificuldades na inclusão e as diferenças entre os bebês com e sem deficiência, pôde-se constatar que o discurso das educadoras parecia mais adequado para as faixas etárias superiores, e não para os bebês de turmas de berçário. Elas mesmas tenderam a mencionar que nos bebês não havia muita diferença entre aqueles com e sem deficiência com relação ao processo inclusivo, o que de certa forma contrariava o discurso anteriormente apresentado que ressaltava dificuldades em incluir bebês com deficiência.

Assim sendo, com base no exposto, é possível constatar que são raros os estudos que investigam a inclusão na etapa de berçário (0 a 24 meses), embora seja um direito do bebê com deficiência a sua matrícula nessa etapa da educação infantil. Desta forma, o objetivo do presente estudo foi investigar os fatores que interferem no processo de inclusão de bebês com deficiência física no berçário, na perspectiva das educadoras.

\section{Método}

\section{Participantes}

Participaram do estudo 11 educadoras de berçário (dez mulheres e um homem) de duas Escolas Municipais de Educação Infantil (EMEI) da cidade de Porto Alegre. Em cada uma das EMEls havia um bebê com deficiência física incluído na turma de berçário. Ambas eram meninas e tinham idades de 18 e 24 meses. A primeira apresentava atraso neuropsicomotor que ocasionava paralisia nos membros superiores e inferiores do lado direito do corpo, o que a impossibilitava de caminhar e de realizar algumas atividades manuais. A segunda bebê também apresentava atraso neuropsicomotor, caracterizado por alteração generalizada do tônus muscular de tronco e membros, de modo que não possuía firmeza nos membros inferiores, o que dificultava a aquisição da marcha. Com relação às educadoras, elas ocupavam diferentes cargos nas EMEls, dependendo do nível de escolaridade, que variou de ensino médio a pós-graduação. A Tabela 1 apresenta os dados sobre as educadoras participantes.

Todas as participantes são integrantes do projeto "A inclusão de bebês com deficiência em creche: programa de intervenção para educadoras com base em conceitos winnicottianos" (Bossi \& Piccinini, 2015) que tem por objetivo investigar as contribuições do Programa de Acompanhamento 
para Educadoras de Creche em Contexto Inclusivo - PRO$\mathrm{AECl}$, para relação educadora-bebê, a partir de conceitos winnicottianos. O projeto contou com três fases de coleta de dados. Na Fase 1 (pré-PROAECI) foram realizadas entrevistas individuais com as educadoras e a filmagem da interação educadoras-bebê com deficiência durante a rotina diária na creche; na Fase 2 (PROAECI), que iniciou uma semana após a fase anterior, foi realizada a aplicação do programa de acompanhamento, que contou com seis encontros individuais para cada educadora, bem como com uma entrevista de avaliação do PROAECI. Por fim, na Fase 3 (pós-PROAECI), realizada dois meses após a fase anterior, foram realizadas novamente as entrevistas individuais e a filmagem da interação educadoras-bebê. Cabe ressaltar que todas as entrevistas e encontros do PROAECI foram realizados nas EMEls em uma sala cedida para esse fim. As EMEls participantes foram contatadas a partir da Secretaria de Educação do Município de Porto Alegre que autorizou a pesquisa.O projeto maior foi aprovado pelo Comitê de Ética da Universidade Federal do Rio Grande do Sul e os participantes assinaram o Termo de Consentimento Livre e Esclarecido (assinado por todas as educadoras e pelas mães das bebês participantes).

\section{Delineamento e instrumentos}

Trata-se de um estudo descritivo e transversal com o objetivo de investigar os fatores que interferem no processo de inclusão de bebês com deficiência física no berçário, na perspectiva das educadoras.

Para fins do presente estudo, foi considerada a "Entrevista sobre a rotina de cuidado de educadoras de creche em contexto inclusivo", aplicada de forma individual durante a Fase 1 (pré-PROAECI). Esta entrevista é composta por um conjunto de questões que abordam as concepções das educadoras sobre os primeiros anos de vida dos bebês, sua rotina de cuidado junto aos bebês com deficiência e a relação com suas famílias. Trata-se de uma entrevista estruturada, realizada de forma semidirigida. Para este estudo, foram particularmente examinadas as seguintes questões: "O que você acha que é necessário para que a inclusão de um bebê ocorra adequadamente?", "Quais as principais dificuldades/barreiras para a inclusão desses bebês na creche?", "O que você considera que facilita a inclusão?". Além disso, também foram considerados para análise dados oriundos da "Entrevista sobre experiência e formação de educadoras de creche em contexto inclusivo", que permitiram caracterizar as participantes.

\section{Resultados}

As respostas à entrevista foram examinadas por meio da análise de conteúdo qualitativa (Laville \& Dionne, 1999). Os relatos das educadoras permitiram identificar diversos fatores que interferem no processo de inclusão, atribuídos: 1) às educadoras; 2) ao bebê com deficiência e seus colegas; e 3) à creche, ao município e a outros profissionais. Para fins de exposição, tais aspectos são destacados separadamente e ilustrados com relatos das próprias participantes. Duas autoras do presente estudo classificaram todas as respostas, de forma independente. Eventuais dúvidas e discordâncias foram discutidas, até que se chegasse a um consenso.

\section{Fatores atribuídos às educadoras}

Nove educadoras ressaltaram, como relatos predominantes, aspectos pessoais e de trabalho didático que tenderam a facilitar a inclusão do bebê com deficiência à creche. $\mathrm{O}$ fato de a educadora possibilitar que o bebê participe de todas as atividades junto aos demais colegas e adaptar essas atividades às suas necessidades foi salientado: "Por mais difícil que seja tu fazer ela participar, tem que fazer, a gente tem que fazer com que ela participe de todos os momentos como se ela fosse igual, como se ela não tivesse aquela dificuldade motora" (E6); "Então eu vejo eles, as gurias às vezes pegam, assim, e começam a cantar com as crianças, sentam e começam a cantar, aí eu vejo a [bebê] lá na almofada, quietinha, sentadinha e eu fico: 'Não, a [bebê] faz parte da turma'. Pego ela no meu colo e ela faz os gestos da forma dela" (E7).

Em vista disso, os relatos trazem que a educadora não deve ter um olhar de "pena" e de "coitadinha" em relação à criança, mas sim um olhar diferenciado para perceber quando ela necessita de maior atenção, de modo a contribuir com o seu desenvolvimento: "Nós, as profes e as estagiárias, não olhar ela com pena, tratando ela diferente" (E2); "No meu modo de ver, eu acho que tem que ter paciência, sabe? Tem que ter aquele olhar diferente que vê que aquela criança precisa de uma atenção maior, né?" (E5); "Tu entender primeiro a demanda dela, qual é a demanda dela, de que forma a gente pode contribuir para ela se desenvolver, e eu acho que esse auxílio, né? Ter esse conhecimento para entender quais são as reais necessidades dela, para a gente saber o que pode fazer no dia a dia pra ela se desenvolver" (E10).

Cabe destacar que uma educadora ressaltou como facilitador da inclusão o fato de as educadoras da turma terem organizado uma rotina diferenciada para o bebê durante os seus primeiros meses na creche, até conhecerem um pouco mais sobre a sua deficiência e suas reais potencialidades e limitações: "No início do ano a gente fazia uma rotina específica para ela, até ter certeza do diagnóstico, porque a gente não sabia realmente que tipo de lesão ela tinha, até onde a gente podia ir, a gente sabia do motor até onde podia ir, mas do neurológico não sabia, então a gente acabava tratando ela com algumas diferenças” (E1). A partir do momento em que já conheciam o bebê, passaram a oferecer atividades adaptadas, mas direcionadas a toda a turma: "A gente está sempre tentando buscar esse trabalho individualizado sem que ele seja visto como individualizado pela criança. Se for promover uma brincadeira motora que precise subir escada, eu estou vendo que ela está com dificuldade de subir a escada, eu não vou propor só pra ela, vou 
propor para a turma inteira e para ela eu vou ter um olhar especial de forma que a turma não perceba isso, que ela não perceba: 'ai eu sou diferente, a profe só fica comigo" (E1).

Ainda, como aspectos facilitadores da inclusão foram citados a importância da educadora procurar se informar e tirar dúvidas sobre a temática, bem como a capacitação profissional: "Ah, eu acho que as pessoas se informarem, eu tenho alguma dúvida, eu vou me informar, vou ler no jornal, vou ver na internet, eu vou procurar o profissional da área, de algum jeito eu vou ter que me informar" (E7); "Primeiro lugar, que eu acho bem importante, acho que é a capacitação do profissional, né?" (E3).

Além disso, cinco educadoras ressaltaram aspectos pessoais e de trabalho didático que tenderam a não facilitar a inclusão do bebê com deficiência à creche. Foram salientados o preconceito do educador, o seu medo de trabalhar com crianças com deficiência e o tratamento dispensado ao bebê, algumas vezes muito diferenciado do das demais crianças: "Acho que o preconceito é a principal barreira" (E7); "Tem que ter um jeito de incluir a criança, se começar a tratar ela muito diferente tu não vai incluir nunca. Porque, né, vai estar excluindo ela do grupo" (E11); "É, ficar com medo de trabalhar com a criança, mas por menos preparado que eu esteja eu acho que tu tem que ter confiança no que vai fazer, né? Segurança no teu trabalho, pra tentar ajudar a criança, né?" (E11).

Consequentemente, também foi salientado como aspecto que não facilitou a inclusão, o despreparo das educadoras para trabalhar com o bebê com deficiência procedente da falta de orientação para as educadoras: "Eu acho que deveria haver um suporte maior nesse sentido, né? Suporte maior, que eu digo, seria de orientação mesmo, suporte especializado" (E9).

\section{Fatores atribuídos ao bebê com deficiência e seus colegas}

Apenas uma educadora ressaltou aspectos pessoais do bebê com deficiência e da relação com os colegas que tenderam a facilitar a sua inclusão na creche. A inteligência do bebê foi salientada como facilitador da inclusão, uma vez que o fazia ser percebido pelas educadoras para além de sua deficiência: "Ela é igual a todo mundo e a gente tenta dar a mesma atenção tanto que, às vezes, a gente acaba esquecendo que ela precisa de uma atenção especial por ela ser tão inteligente" (E1). A educadora ainda mencionou que a inclusão parecia ser facilitada pela ajuda das outras crianças da turma que auxiliavam a colega com deficiência: "Ela está sendo bem incluída. Inclusive os colegas assumem ela, ajudam ela..., as próprias crianças dão atenção pra ela” (E1).

Essa mesma educadora também destacou aspectos pessoais da bebê que tenderam a não facilitar a sua inclusão. Foi enfatizado que em razão da deficiência, a criança cansava mais e isso acabava dificultando a realização de atividades: " $A$ [bebê] tem uma peculiaridade que é realmente, de manhã ela tá muito descansada e eu realmente consigo fazer muita coisa com ela, e à tarde ela se cansa muito em função da própria deficiência e ela já não faz tantas atividades motoras como faz de manhã"(E1).

\section{Fatores atribuídos à creche, ao município e a outros profissionais}

Quatro educadoras ressaltaram fatores do trabalho na escola e com outros profissionais que tendem a facilitar a inclusão do bebê com deficiência. Foi destacada a importância de esse bebê encontrar na creche um ambiente acolhedor e adequado às suas necessidades, além da escola ser adaptada para receber o aluno com deficiência: "Um ambiente acolhedor, um ambiente em que a criança seja realmente inclusa, que isso é muito importante" (E3); "A escola tem que ser adaptada, os profissionais tem que ser preparados, eu acho isso". (E11).

Uma educadora ainda salientou a importância de a creche realizar um trabalho voltado para a inclusão com toda a equipe escolar e de haver uma periodicidade maior de assessoria da secretaria de educação à escola: "Eu acho que um trabalho inclusivo bom tinha quer ser feito a escola toda em equipe, sabe? Todo mundo tinha que saber que ela é inclusão. Acho que era a principal coisa pra todo mundo estar podendo ajudar, né? Eu acho, assim, que a nossa assessora tinha que vir aqui todo o mês olhar ela, não tem que vir quando surge um problema, tinha que vir todo o mês aqui. Isso faz parte do trabalho inclusivo" (E4).

Também foi destacada como facilitador da inclusão a ajuda de outros profissionais, como fisioterapeutas, que auxiliam no desenvolvimento das habilidades do bebê: "Então tem que ter o amparo, né? A criança precisa ter um apoio, um suporte externo de profissionais" (E11).

Além disso, todas as educadoras mencionaram, como relatos predominantes, aspectos concernentes aos recursos materiais e humanos da creche que tenderam a não facilitar a inclusão no berçário. Os relatos se referiram à ausência de mais um profissional em sala que pudesse auxiliar nos cuidados e estimulação do bebê com deficiência. Ainda, a necessidade de ser um profissional especializado em educação inclusiva, também foi destacada: "Mas se tivesse alguém, de repente, uma quarta pessoa na sala, a gente poderia fazer um trabalho mais orientado para ela" (E1); "É tu ter as pessoas certas trabalhando, tu colocar um estagiário de história pra ser o monitor que vai ajudar a inclusão, não é inclusão, não é ajudar, tem que ter uma pessoa que tenha uma especialização em educação inclusiva pra trabalhar a inclusão" (E4). A dificuldade em conseguir um profissional extra na escola se devia, principalmente, a falta de diagnóstico preciso da deficiência do bebê: "Conseguir o diagnóstico que é fundamental, porque sem o diagnóstico a gente não consegue pedir uma monitora a mais, que dá para fazer pela secretaria de educação, por exemplo. Tu não tem o diagnóstico fechado e daí tu não tem o apoio que tu deveria receber com o diagnóstico e a criança acaba tendo mais 
dificuldades para se desenvolver em uma fase que é crucial para o desenvolvimento dela, que é até os 3 anos" (E1).

Já com relação à estrutura física da escola, foram salientados aspectos relacionados à limpeza e à ausência de barras na sala e outras adequações a fim de oferecer acessibilidade a bebê com deficiência: "Limpeza seria um ponto a considerar, assim, porque a [bebê] anda imunda, né? Ela anda muito no chão. Ela se arrasta e poderia ter uns corrimões na sala para ela se apoiar, porque aí ela não precisaria tanto do nosso auxílio" (E6).

Acerca do município, representado pela secretaria de educação, foram ressaltados pelas educadoras como aspectos que não facilitam a inclusão o não oferecimento de cursos e/ou palestras sobre o tema, a falta de material didático sobre inclusão (livros, vídeos, etc.) e o fato de o município não dispor de mais funcionários a fim de atender a demanda de um monitor em sala: "Orientação, assim, de como trabalhar com ela, da secretaria de educação a gente não tem, né? Isso seria importante ter, dar o fundamento para a gente conseguir trabalhar com ela" (E7); "Acho que é um olhar lá de cima mesmo. Aqui é uma escola da prefeitura, eu acho que então a gente depende muito do município, porque muitas vezes não acontece, não é nem por causa da direção, é por coisa lá de cima. Não tem funcionário, não oferecem curso de capacitação para os educadores, para os professores, enfim, né? Acham que a escolarização, o estudo do professor é o suficiente, mas não é" (E3); "Por isso que eu digo, eu acho que esse processo de inclusão na prefeitura tá muito na fase inicial ainda" (E9).

Também foi ressaltado como não facilitador da inclusão a falta de comunicação com os outros profissionais (como fisioterapeutas) que atendem o bebê: "Eu acho que tem que ter mais comunicação, informações dos profissionais externos que a criança vai buscar recurso. Acho que isso facilitaria bastante" (E11); "Me parece que algumas coisas acontecem de forma isolada, estanque. Por exemplo, num processo inclusivo, minha concepção é outra, eu penso de outra forma, tem que ser em conjunto, por isso que é um processo. Então eu acho, assim, que teria muito mais efeito, muito mais progresso, se a gente pudesse sim ajustar um pouco essa relação, a questão do próprio atendimento [fisioterapia] também, né? $E$ da gente poder ter um pouco esse retorno, ter orientação nesse sentido" (E7).

\section{Discussão}

Os resultados revelaram diversos fatores que interferemno processo de inclusão de bebês com deficiência física no berçário, atribuídos, principalmente, às educadoras, aos bebês com deficiência e seus colegas, à creche, ao município e a outros profissionais. Com isso, percebe-se a complexidade do fenômeno estudado, uma vez que tende a envolver não somente as educadoras e os bebês com deficiência, mas também outros implicados nesse processo, como a equipe escolar, a secretaria municipal de educação e os profissionais da saúde. Com relação a esse último aspecto, destaca-se também a importância dos profissionais da assistência social, embora não mencionados pelas educadoras desse estudo. Isso porque o processo inclusivo deve envolver a intersetorialidade entre educação, saúde e assistência social, a fim de possibilitar a garantia de direitos à pessoa com deficiência. No entanto, tal prática ainda se apresenta como um desafio para os profissionais dos diferentes campos, visto que as áreas ainda costumam atuar de forma setorializada, o que dificulta a implantação efetiva da política de inclusão social e escolar (Pereira \& Teixeira, 2013). Por isso, a queixa apresentada pelas educadoras de que não havia diálogo entre elas e os profissionais de fisioterapia que atendiam os bebês incluídos no berçário, visto que não havia busca, de nenhum dos lados, a fim de efetivar essa parceria.

Com relação aos fatores que interferem na inclusão atribuídos às educadoras (e por elas) do presente estudo, predominou aqueles que tendem a facilitar o processo inclusivo (tais como a adaptação de atividades às necessidades do bebê com deficiência, um olhar diferenciado a fim de o auxiliar em seu desenvolvimento, e a capacitação das educadoras) em detrimento dos não facilitadores (despreparo das educadoras em educação especial e inclusiva, e o preconceito e medo das educadoras com relação à inclusão). Isso pode ter se dado pelo fato de que as educadoras estavam falando delas mesmas e de seu trabalho atual com o bebê com deficiência atendido em sua turma, o que possibilitou que mais aspectos favoráveis à inclusão fossem destacados.

O contrário se deu com relação aos fatores atribuídos à creche, ao município e a outros profissionais em que predominaram os fatores não facilitadores, tais como a ausência de recursos materiais e humanos na escola e o não oferecimento de capacitação às educadoras. Nesse sentido, cabe salientar o fato de a escola não conseguir um profissional extra (monitor) para a turma de berçário por falta de diagnóstico preciso da deficiência do bebê. A necessidade de um diagnóstico médico é algo usualmente exigido no contexto escolar e social (em caso de concurso público, por exemplo, é exigido o atestado com o diagnóstico para fins de concorrência dentro das cotas destinadas a pessoas com deficiência). No entanto, isso vai contra a atual política de inclusão estabelecida pelo Estatuto da Pessoa com Deficiência (Lei n 13.146, 2015) e a concepção de diagnóstico biopsicossocial preconizada pela Organização Mundial de Saúde (2012). O diagnóstico biopsicossocial defende a interação dinâmica entre fatores da pessoa com deficiência e fatores do ambiente que interferem em seu processo inclusivo. Assim, apenas a exigência de um atestado médico exclui os fatores ambientais como importantes para o diagnóstico e para a inclusão dos bebês com deficiência. Dessa forma, a queixa das educadoras com relação a esse aspecto sinaliza algo que precisa ser revisto dentro dos contextos educacional e social brasileiros.

Destaca-se, ainda, como relevante, o fato de apenas uma educadora ter ressaltado fatores que interferem na inclusão, referentes ao bebê com deficiência e seus colegas, os avaliando como parte desse processo, ainda mais ao considerar o bebê para além de sua deficiência, salientan- 
do sua inteligência, por exemplo, que impactava de forma positiva em sua inclusão. Isso sem deixar de destacar as características da deficiência que colocavam maiores dificuldades motoras relacionadas ao bebê e a sua acessibilidade na escola, impacto da falta de recursos materiais na creche. Tal fato apresenta-se como diferenciado do encontrado na literatura, em que predomina o discurso das educadoras com relação à deficiência como algo que limita o desenvolvimento da criança, sem que se consiga ter um olhar voltado às potencialidades do bebê que podem o auxiliar no processo inclusivo (Vitta, 2010).

Cabe ressaltar que os fatores que interferem no processo inclusivo de bebês com deficiência física no berçário,destacados pelas participantes desse estudo, estão na direção dos encontrados na literatura (Dantas, 2012; Fragoso \& Casal, 2012; Galceran, 2012; Vitta, 2010; Zucchetti, 2011). No entanto, chama atenção o fato deque nenhum fator associado às famílias dos bebês com deficiência foi mencionando como interferindo no processo de inclusão. As educadoras não salientaram a família como um agente promotor da inclusão, o que tem sido destacado em alguns estudos (Maturana \& Cia, 2015) que ressaltam a relação família-escola como um facilitador da inclusão. Cabe frisar que a revisão de literatura de Maturana e Cia (2015) envolveu teses e dissertações produzidas entre 2001-2011 sobre a relação família-escola com crianças público-alvo da educação especial, e encontraram poucos estudos que investigam a participação da família nesse contexto de inclusão, o que coloca a relevância de maiores investigações científicas nesta temática.

Sugere-se também que outros estudos investiguem a inclusão na concepção dos demais agentes escolares, como diretoras, supervisoras e equipe de funcionárias da alimentação e limpeza, que também fazem parte da escola e contribuem para esse processo inclusivo. Até mesmo, as educadoras do presente estudo ressaltaram a importância de a inclusão ter de ocorrer na equipe escolar como um todo, e não somente com as educadoras do bebê com deficiência, o que está de acordo com o preconizado na literatura (Dantas, 2012; Zucchetti, 2011).

\section{Considerações Finais}

O presente estudo investigou o relato das educadoras referente aos fatores que interferem no processo inclusivo de bebês com deficiência física em turmas de berçário. Foi possível identificar diversos fatores referentes aos diferentes atores que promovem a inclusão, sendo as educadoras; os bebês com deficiência física; a creche, o município e outros profissionais. Diferentes aspectos foram ressaltados, que permitem afirmar o quanto a temática da inclusão precisa ser melhor investigada na educação infantil, em particular na etapa de berçário, foco do presente estudo.

Nesse sentido, cabe ressaltar que mesmo transcorridos mais de duas décadas de políticas de educação na perspectiva inclusiva (i.e. Declaração de Salamanca - Unes- co, 1994; LDB - Lei n 9.394, 1996), pôde-se constatar, no discurso das educadoras, que a inclusão ainda está sendo realizada de forma incipiente, sem que se dedique prioridade de investimentos na educação, como sugere a atual legislação. Isso indica que muito ainda precisa ser feito pelas várias instâncias envolvidas com a inclusão, particularmente na educação infantil, que precisa envolver as famílias como coparticipantes desse processo. Também se coloca a necessidade de se avançar em termos de pesquisa e intervenção, ao incentivara parceria escola-universidade, que pode proporcionar a promoção da inclusão nos seus aspectos interdisciplinares e de intersetorialidade, contribuindo para qualificar o processo inclusivo.

\section{Referências}

Al-Yagon, M.; Aram, D.; Margalit, M. (2016). Early childhood inclusion in Israel. Infant \& Young Children, 26(3), 205-213.doi: 10.1097/IYC.0000000000000063.Recuperado:11 maio 2017. Disponível:https://eric.ed.gov/?id=EJ1103462.

Bossi, T. J.; Piccinini, C. A. (2015). A inclusão de bebês com deficiência em creche: programa de intervenção para educadoras com base em conceitos winnicottianos. Projeto de Pesquisa não publicado. Porto Alegre: Universidade Federal do Rio Grande do Sul.

Brandão, M.T.; Ferreira, M. (2013).Inclusão de crianças com necessidades educativas especiais na educação infantil. Revista Brasileira de Educação Especial, 19(4), 487-502. Recuperado: 09 mar. 2017. Disponível:http://www.scielo.br/scielo.php?script=sci_ arttext\&pid=S1413-65382013000400002.

Brasil (1998). Referencial curricular nacional para a educação infantil. Brasília: Ministério da Educação.

Brasil. Secretaria de Direitos Humanos da Presidência da República (2012). Cartilha do Censo 2010: pessoas com deficiência. Brasília: SDU/PR.

Brodzeller, K. L.; Ottley, J. R.; Jung, J.; Coogle, C. G. (2017). Interventions and adaptations for children with autism spectrum disorder in inclusive early childhood settings. Early Childhood Educational Journal, 1-10. doi: 10.1007/s10643-017-0859-5. Recuperado: 11 mai. 2017. Disponível: https://link.springer.com/ article/10.1007/s10643-017-0859-5.

Dantas, P. F. R. (2012). Concepções e práticas pedagógicas de professoras da educação infantil na inclusão de alunos com deficiência. Dissertação de mestrado, Universidade Federal do Rio Grande do Norte, Natal.

Fragoso, F. M. R. A.; Casal, J. (2012). Representações sociais dos educadores de infância e a inclusão de alunos com necessidades educativas especiais. Revista Brasileira de Educação Especial, 18(3), 527-546. doi: 10.1590/ S1413-65382012000300011. Recuperado: 09 mar. 2017. 
Disponível: $\quad$ http://www.scielo.br/scielo.php?pid=S141365382012000300011\&script=sci_abstract\&tlng=pt.

Galceran, N. B. (2012). Representação social do professor em relação à inclusão escolar de crianças com deficiência. Dissertação de mestrado, Universidade de São Paulo: São Paulo.

Instituto Nacional de Estudos e Pesquisas Educacionais Anísio Teixeira [INEP] (2014). Censo escolar da educação básica 2013. Brasília: O Instituto.

Laville, C.; Dionne, J. (1999). A construção do saber: manual de metodologia da pesquisa em ciências humanas. Porto Alegre: Artmed.

Lei No 9.394, de 20 de dezembro de 1996 (1996, 20 de dezembro). Estabelece as diretrizes e bases da educação nacional. Brasília: Senado Federal.

Lei No 13.146, de 6 de julho de 2015 (2015, 6 de julho). Institui a Lei Brasileira de Inclusão da Pessoa com Deficiência. Brasília: Senado Federal.

Lemos, E. L. M. D.; Salomão, N. M. R.; Agripino-Ramos, C. S. (2014). Inclusão de crianças autistas: um estudo sobre interações sociais no contexto escolar. Revista Brasileira de Educação Especial, 20(1), 117-130.doi: 10.1590/S1413-65382014000100009. Recuperado: 09 mar. 2017. Disponível: http://www.scielo.br/scielo. php?script=sci_arttext\&pid=S1413-65382014000100009.

Majoko, T. (2016). Inclusion in early childhood education: pre-service teachers voices. Early Child Development and Care, 186(11), 1859-1872. doi: 10.1080/03004430.2015.1137000 Recuperado: 11 mal. 2017. Disponível: https://www.tandfonline.com/doi/abs/10. 1080/03004430.2015.1137000?journalCode=gecd20

Maturana, A. P. P. M.; Cia, F. (2015). Educação especial e a relação família-escola: análise da produção científica de teses e dissertações. Psicologia Escolar e Educacional, 19(2), 349-358. doi: 10.1590/2175-3539/2015/0192849. Recuperado: 09 mar. 2017. Disponível: http://www.scielo.br/scielo.php?pid=S141385572015000200349\&script=sci_abstract\&tlng=pt

Organização das Nações Unidas para a Educação, a Ciência e a Cultura [UNESCO] (1994). Declaração de Salamanca sobre princípios, política e práticas na área das necessidades educativas especiais. Salamanca: UNESCO.
Organização Mundial da Saúde [OMS] (2012). Relatório mundial sobre a deficiência / World Health Organization, The World Bank, São Paulo: SEDPcD.

Pereira, K. Y. L.; Teixeira, S. M. (2013). Redes e intersetorialidade nas políticas sociais: reflexões sobre sua concepção na política de assistência social. Textos \& Contextos, 12(1), 114-127. Recuperado: 09 mar. 2017. Disponível: http://revistaseletronicas. pucrs.br/ojs/index.php/fass/article/view/12990

Sanini, C.; Bosa, C. A. (2015). Autismo e inclusão na educação infantil: Crenças e auto eficácia da educadora. Estudos de Psicologia, 20(3), 173-183. doi: https://dx.doi.org/10.5935/16784669.20150019. Recuperado: 09 mar. 2017. Disponível: http:// www.scielo.br/pdf/epsic/v20n3/1413-294X-epsic-20-03-0173.pdf

Sucuoglu, B.; Bakkaloglu, H.; Karasu, F. I.; Demir, S.; Akalin, S. (2014). Preschool teachers' knowledge levels about inclusion. Educational Sciences: Theory \& Practice, 14(4), 1477-1483. doi: 10.12738/ estp.2014.4.2078 Recuperado: 11 mai. 2017. Disponível: http:// oldsite.estp.com.tr/pdf/en/58d93349de1 baff4e58c16fd4848e 9f671483.pdf

Vitta, F. C. F. (2010). A inclusão da criança com necessidades especiais na visão de berçaristas. Cadernos de Pesquisa, 40(139), 75-93. doi: 10.1590/S0100-15742010000100005 Recuperado: 09 mar. 2017. Disponível: http://www.scielo.br/scielo.php?pid=S0100$15742010000100005 \&$ script=sci_abstract\&tlng=pt.

Vitta, F. C. F.; Silva, K. P. L.; Moraes, M. C. A. F. (2004). Conceito sobre a educação da criança deficiente, de acordo com professores de educação infantil da cidade de Bauru. Revista Brasileira de Educação Especial, 10(1), 43-58. Recuperado: 09 mar. 2017. Disponível: http://www.abpee.net/homepageabpee04_06/artigos_ em_pdf/revista10numero1pdf/4vittaetal.pdf

Vitta, F. C. F.; Vitta, A.; Monteiro, A. S. R. (2010). Percepção de professores de educação infantil sobre a inclusão da criança com deficiência. Revista Brasileira de Educação Especial, 16(3), 415428. doi: 10.1590/S1413-65382010000300007. Recuperado: 09 mar. 2017. Disponível:http://www.scielo.br/scielo.php?pid=S1413$65382010000300007 \&$ script=sci_abstract\&tlng=pt

Zucchetti, D. T. (2011). A inclusão escolar vista sob a ótica de professores da escola básica. Educação em Revista, 27(2), 197-218. doi: 10.1590/ S0102-46982011000200010. Recuperado: 09 mar. 2017. Disponível: http://www.scielo.br/scielo.php?script=sci_abstract\&pid=S010246982011000200010\&lng=pt\&nrm=iso\&tlng=en

Recebido em: 13 de junho de 2017 Aceito em: 23 de outubro de 2017 unrestricted use, distribution and reproduction in any medium, provided the original article is properly cited. 